\title{
Systematic violations of patients' rights and safety: Forced medication of a cohort of 30 patients
}

\author{
PETER C GøTZSCHE, ANDERS SøRENSEN
}

\begin{abstract}
We assessed the records for 30 consecutive patients who had appealed decisions about forced medication with antipsychotics to the Psychiatric Appeals Board in Denmark. In all 21 cases where there was information about the effects of previous drugs, the psychiatrists stated that antipsychotics had had a good effect whereas none of the patients shared this view. The harm caused by earlier or currently used antipsychotics did not seem to have played any role in the psychiatrists' decision-making. The legal requirements for using force to protect the patients' health were never met and less intrusive treatments than antipsychotics, eg, benzodiazepines or psychotherapy, were never mentioned as options. The power imbalance was extreme, the patients felt misunderstood and ignored, their legal protection was a sham, and the harm done was immense. The violation of patient rights is a global problem. We suggest that forced medication be abandoned.
\end{abstract}

Keywords: antipsychotics; forced treatment; patient rights

\section{Introduction}

Forced treatment with psychiatric drugs is highly controversial. It violates basic human rights and discriminates against psychiatric patients. The United Nations Convention on the Rights of Persons with Disabilities has therefore called for the abolition of mental health laws that permit forced treatment (1).

As we shall discuss further below, the benefits from antipsychotics are so uncertain and the harm so pronounced that it is not clear that forced treatment is in the patients

Authors: Peter C Gøtzsche (pcg@scientificfreedom.dk), Professor, Institute for Scientific Freedom (https://www.scientificfreedom.dk/), Copenhagen, DENMARK; Anders Sørensen (anders.ks90@gmail.com), Psychologist and PhD student, Institute for Scientific Freedom, Copenhagen, DENMARK.

To cite: Gøtzsche PC, Sørensen A. Systematic violations of patients' rights and safety: Forced medication of a cohort of 30 patients. Indian J Med Ethics. 2020 Oct-Dec;5(4) NS: 312-8. DOI: 10.20529/IJME.2020.085.

Published online on August 12, 2020.

Manuscript editor:Vijayaprasad Gopichandran

Peer Reviewers:Two anonymous reviewers

(c) Indian Journal of Medical Ethics 2020 best interests (2-6). In Norway, forced drugging is only allowed when, with "high probability, it can lead to recovery or significant improvement in the patient's condition, or if the patient avoids a significant worsening of the disease." (7). Other countries have similar laws; the Norwegian Ombudsman concluded in December 2018 that the Psychiatry Act had been violated in a specific case because the randomised trials showed that the probability of achieving the intended improvement was low (7).

In an earlier cohort study of 30 patients, we showed that the Psychiatric Appeals Board in Denmark focuses on uncontroversial issues that are easy to check when patients appeal forced treatment orders (8). This seems mainly to have a cosmetic function and inevitably rubber stamped the views and arguments put forward by the psychiatrists.

As the Psychiatric Appeals Board has consistently avoided dealing with issues of crucial importance to patients, we decided to study these in detail in the same cohort of cases (8).

\section{Methods and materials}

In Denmark, a patient can complain about forced medication to the Psychiatric Patients' Complaints Board, and if the decision is upheld, the patient can appeal to the Psychiatric Appeals Board, whose decision is final.

The Appeals Board granted us access to the records of the 30 patients most recently subjected to forced medication. We needed to sign a confidentiality agreement and to read the material and extract data during visits to the Appeals Board offices. We were not allowed to make photocopies or to reveal the identities of the patients, psychiatrists, or departments involved. Permission from a research ethics committee was not required.

All the material handed out to us was on paper. It consisted of selected parts of the patients' files, their complaints to the board (in two cases, psychiatrists complained that their decision about forced treatment had been overruled by the Complaints Board), medical certificates, expert assessments by psychiatrists, and meeting notes.

We extracted data at the Appeals Board offices between January 30 and April 24, 2018. For data extraction, we used a form with subheadings where we noted why the patients refused treatment with antipsychotics, the benefits and harms of previous drugs, any mention of less intrusive treatments like 
benzodiazepines or psychotherapy, signs and symptoms of psychosis, indirect coercion, motivation to take the medicine, expert assessments, and whether the patient was being ignored. When in doubt, we consulted each other and often also a psychiatrist, who participated in some of the data extraction sessions.

Our main objectives were to assess if the arguments for using force were reasonable and evidence-based while taking the patients' views into account, including their previous experiences with antipsychotics and if they were being treated with respect and dignity.

\section{Results}

The median year of birth for the 30 patients was 1970 (range 1935 to 1996$)$ and 16 were males.

\section{No respect for poor benefit or harms of previous drugs}

In all 21 cases where there was information about this, the psychiatrists stated that previous antipsychotics had had a good effect whereas none of the patients shared this view. Even for a patient whose psychosis had worsened, the psychiatrist noted that the treatment was effective, and when a high dose had not worked for another patient, a further dose increase was nonetheless deemed "absolutely necessary".

All improvements were ascribed to the drugs, even in a case where it took a "long time" before any change was observed. We did not find any comments about a possible spontaneous improvement. In three cases, the patients had not taken antipsychotics before, and in ten cases, we did not find any information about previous harms. The harmful effect of earlier or currently used antipsychotics did not seem to have played any role in the psychiatrists' decision-making, even when they were serious.

An expert confirmed our suspicion that a patient had developed akathisia on aripiprazole; but on the same page stating this, the expert - a high-ranking member of the board of the Danish Psychiatric Association - recommended forced treatment with this drug even though it had been stopped because of the akathisia. Another patient suffered from uneasiness, "inner cramps", and involuntary movements on zuclopenthixol, which might represent akathisia or tardive dyskinesia. Even though the Appeals Board noted this, it was not opposed to forced treatment with this drug. A third patient had tongue protrusion, but it was not mentioned that it could be an effect of antipsychotics (tardive dystonia).

A fourth patient had clear signs of tardive dyskinesia including tics, odd facial movements, and twisted and involuntary movements, as confirmed by a physiotherapist, but this diagnosis did not appear anywhere in her file. It was highly likely that a fifth patient had tardive dyskinesia, but the psychiatrists ascribed her symptoms to her disease. We suspected tardive dyskinesia in two more patients who were nonetheless forced to take antipsychotics. Four patients said that the drug made them lethargic, two of them describing the experience as "the brain dries out" and "you might as well remove my brain".

\section{Feeling unsafe}

In five cases, the patients expressed fear of dying because of the forced treatment: "the drugs kill you"; "Either I kill him, or he kills me with his shitty medicine"; "my father died because of intoxication with psychiatric drugs". Another patient could not tolerate the medication and was very scared that the staff might kill her. Yet another patient, who had received clozapine earlier, said "I don't want to die." On admission, she was in treatment with dangerous polypharmacy consisting of clozapine tablets, aripiprazole depot injections, and sertraline along with tizanidine, clonazepam, and promethazine as needed for sleeping problems. A sixth patient felt very unsafe, but the staff had not asked why, even though she had spoken about being abused.

\section{Tranquillising the department by tranquillising the patients}

In five cases, the explicit purpose of forced treatment was to prevent the patients from disturbing the staff and other patients. A statement like, "We would like to help her with a tranquilliser as needed," raises the question: help whom? Two of the patients did not have convincing signs of acute psychosis, but one of them received an injection of depot zuclopenthixol, which seems to be a disproportionate use of force for a noise problem.

\section{Less intrusive treatments never used}

Benzodiazepines or psychotherapy were never mentioned as options. Only in one case was there any indication that a patient might have received psychotherapy: "Continues talks with a psychologist."

Seven patients asked for a psychologist, but this seemed not to have been granted. In one case, the psychiatrist argued that the patient's condition was too poor for her to benefit from it but added that his judgement "of course can be discussed". He noted that the patient looked down on psychiatry and had said that it did not offer psychotherapy, but he did not see the irony that he had just confirmed this himself. The patient was described as being "condescending and provocative when the staff gives her the drugs," which she did not tolerate, not even in low doses, saying,"I shall get my poison."

Psychoeducation was mentioned three times but for another purpose, eg, "to motivate for a life-long drug treatment", which we find questionable given the serious long-term harmful effects of these drugs $(4,6-9)$.

\section{Questionable diagnoses of delusions}

We had reservations about the psychiatrists' diagnoses of delusions in nine cases. When a patient rejected olanzapine totally, this was called a persecutory delusion; another patient who became "hotheaded and difficult to communicate with" as soon as an antipsychotic was mentioned, was called "paranoid and conspiratorial about how we rally against him". 
The patient mentioned above, with clear signs of tardive dyskinesia, was said to have psychotic misconceptions about the "postulated side effects". When a patient on voluntary admission mentioned that she was served meat during her last hospitalisation even though she was a vegetarian, this was interpreted as a delusion.

A patient was said to have several delusions about hospitals and apparently also about drugs, as he would only take supplements and homoeopathy. His own view was that he had become psychotic because of the medicine. This might be true $(6,9)$, and it is not a delusion to be afraid of hospitals or to use alternative medicine. A patient was diagnosed with religious delusions because he had said that Jesus could remove a cancer without leaving scar tissue. It is not accepted practice to diagnose delusions in people because of their religious beliefs.

A patient known to have bipolar disorder, who had not been in contact with psychiatry for ten years, was admitted after a stressful period where she had been harassed by a neighbour. This was called a delusion, with no insight into the disease. Based on the colourful descriptions of her behaviour, including that she was being ironic and bothered other patients, it is difficult to judge whether she was delusional. No examples were provided of her alleged private logic (which many people have) or the alleged paranoid interpretations.

A patient who wanted to complain about being subjected to forced medication was called delusional because, according to his file, force was not applied. However, force is often applied indirectly, and the patient file belied the diagnosis of delusion: "Is offered olanzapine $20 \mathrm{mg}$ again and agrees to take this under force".

"The patient still has no disease insight and says that her feelings disappeared after she tried to take medication." It is well-known that psychiatric drugs often make people emotionally numb $(5,6,9)$. This fact cannot be used to diagnose a delusion.

\section{Case stories about lack of respect for patients}

A patient who did not want a sedative and had not bothered anyone was given an injection with $10 \mathrm{mg}$ diazepam by the chief psychiatrist who argued, contrary to the notes in the patient's file, that the patient had been uneasy, had severe anxiety, and had a "certain aggressive potential". The psychiatrist also argued that the patient "had severe catatonia, a potentially life-threatening condition".When he was overruled by the expert assessment, the Complaints Board and the Appeals Board, he described this as "a lack of insight into the psychiatric sphere of action". When the patient developed a headache on haloperidol, he doubled the dose of haloperidol injections without giving any reason, although headaches are a well-known harm of this drug.

A patient who would rather go to jail than be given drugs and who had become lethargic while receiving three antipsychotics with additional drugs was said not to have experienced "inappropriate side effects". Even though he was not psychotic and was already overtreated, the psychiatrist found it advisable to intensify the treatment and did not consider that the patient's aggression might have been caused by the drugs or the additional forced treatment to which he was subjected.

A patient who firmly refused to take drugs was "offered" a haloperidol tablet as a sleeping pill even though its sedative effect is poor, and when she lashed out at the hand of the caregiver who gave her the pill and shouted that the staff should leave her room, she was judged to be in an "affective state". When they had left, she became calm, but a plan was made that if she was not asleep around midnight, but was pained, uneasy, shouting and outwardly reacting, she would be treated with haloperidol, possibly as an injection, "to maintain a sufficient sleeping pattern". The medical certificate noted that a less intrusive treatment than antipsychotics would be inadequate but there was no explanation why, and the expert claimed that she was treated to preserve her health.

A patient who refused to take drugs because they did not work and because he had suffered multiple harmful effects on olanzapine including weight increase, tiredness, lethargy, nausea, stomach pain, dry mouth, difficulty watching TV, and possibly also akathisia or tardive dyskinesia, was very agitated on forced admission. Otherwise, he was quite peaceful and did not appear to be psychotic, eg, it was possible to have conversations with him about "neutral subjects". The expert resolved that he needed drugs to preserve his health. It was also incomprehensible to us why he was hospitalised for an exceedingly long time. After three months, he was clearly burdened with being hospitalised, and after four months, he was said to have no realisation of his need for treatment. It seemed to us to be the other way around: the psychiatrists had no realisation of his need to be medicine-free.

A patient admitted voluntarily asked for $2.5 \mathrm{mg}$ olanzapine, and when the psychiatrist talked about $10 \mathrm{mg}$ and a long stay at the ward, he became angry. Only one day after his voluntary admission, he was told that if he refused, he would be given an injection. The Appeals Board approved the use of force because the patient had threatened to kill staff, was extremely derogatory towards the chief psychiatrist, and went into a serious affective state several times when the psychiatrist tried to return him to his room. There was no reflection on his behaviour possibly being a result of the way he was being treated.

"The patient has been dismissive and refused to talk to doctors but is kind to nursing staff ... she gets very angry when we try to motivate her; will not say why she refuses to take drugs but asks me to try them for myself." The patient informed the Complaints Board that the arguments used to compel her were all false and inadmissible, and we found her arguments to be convincing. Earlier, the dose was reduced because of sedation and because she had experienced tremors of the hands and neck, which could be due to tardive dyskinesia; however, according to the notes, she was responding well to zuclopenthixol. 
A manic patient who had threatened to kill people received an olanzapine injection when he started to shout and threaten. The nursing records were revealing: "The patient says that it is through contact with staff he feels pressured and becomes upset ... the patient has been threatening and noisy, but the staff has been able to correct him."

A patient with a verdict confining him to a forensic psychiatric hospital indefinitely did not respond to the medicine and was bothered by harmful effects even on small doses. The psychiatrist's response was to increase the treatment. The patient was described as "quarreling, provocative and speaking in a condescending tone", but he and his brother felt it was the staff that was provocative. The patient had "catatonic movements in the form of strange and sudden movements". When he deteriorated following pressure from himself and the family to reduce the dose, this was explained by his disease even though catatonia might be a drug harm worsened by withdrawal effects (10).

About a patient who refused to take olanzapine because it had no effect, the psychiatrist opined he was "well treated with olanzapine" and that "the effect of the drug is well documented". He further noted that the patient "sees the forced interventions as themes for the upcoming patient Complaints Board meeting". Such arrogance is not helpful for patients.

A patient who said that the dopamine hypothesis about schizophrenia doesn't hold, that he had experienced serious harms on antipsychotics and did not want them, and that he had experienced good results from benzodiazepines, was subjected to forced treatment with an antipsychotic. On this treatment, he developed seizures and was unable to think.

A homeless patient, not previously known to psychiatry, said that she did not need to be medicated because she did not present a risk to others and was not uneasy. She was forcefully treated with a "tranquilliser" (olanzapine) because she was said to be increasingly agitated, uneasy, and pained. When she got very upset over the use of force, she was put in belts.

A young woman reported that she was sexually abused as a child and had cut off contact with her family. She was admitted voluntarily, and when she could not be discharged, she became highly agitated, shouted, and felt threatened by a male patient. She was forcefully treated with $20 \mathrm{mg}$ olanzapine two days later. A week later, the diagnosis of schizotypy was changed to schizophreniform psychosis. It was not considered that her behaviour and symptoms might have been caused by the staff or the medication.

\section{Discussion}

The power imbalance and abuse we found was extreme. The psychiatrists did what they wanted to the patients and consistently ignored their wishes, trauma, and other experiences. What some patients had to endure was outright dangerous and it was reasonable that some of them were afraid they might get killed by the drugs that were enforced upon them.
The patients are defenceless in such a system. All the way up to and including the Psychiatric Appeals Board (8), the psychiatrists' views and decisions were being supported and the various experts paid lip service to the law. For example, one noted: "It was not acceptable to dose this way ... but my assessment is of an academic character." The expert reports were brief summaries of the cases that did not contribute anything substantial.

\section{Habitual lying}

A patient who perceived herself as being traumatised and not having "biological schizophrenia" found it unbelievable that she would not be allowed to participate in the meeting that would decide on her fate, but that the Appeals Board would make a decision based on what was submitted to them. In the US, it has been documented that psychiatrists, with the full understanding and tacit permission of trial judges, regularly lie in court to obtain involuntary commitment and forced medication orders (11). Psychiatrist Fuller Torrey, probably the most prominent proponent of involuntary psychiatric treatment, has said that it would probably be difficult to find any American psychiatrist who has not exaggerated the danger posed by a mentally ill person's behaviour to obtain a judicial order for commitment (11). Quoting another psychiatrist, he has also said that this lying is a good thing: "Confronted with psychotic persons who might well benefit from treatment, and who would certainly suffer without it, mental health professionals and judges alike were reluctant to comply with the law."

However, the professional "We know what is best for you" attitude is not only fallacious, it also leads to habitual lying and to ignoring the law and patients' basic rights. This is horrific, not least because it leads to thousands of deaths every year and likely millions of cases of serious brain damage worldwide, including tardive dyskinesia (6).

There is no sound scientific basis for the use of antipsychotics. All the placebo-controlled trials are biased because the conspicuous side effects mean that the trials were not effectively blinded (6). Furthermore, some or all patients were already in treatment before they were randomised (12), which means that patients in the placebo group were subject to withdrawal symptoms. Even though the trials were seriously biased (6) and though it is easy for scores to improve quite a bit if people are knocked out by a tranquilliser and express their abnormal ideas less frequently (4), the trials have not found a relevant effect. The minimal improvement corresponds to about 15 points on the Positive and Negative Syndrome Scale (PANSS) (2), but what was obtained in recent placebo-controlled trials in submissions to the FDA was only 6 points (3).

In our systematic review from 2019, we found only one trial of drug-naïve patients, but it was unreliable; a huge effect in favour of placebo over olanzapine was reported (12). In March 2020, the second trial in drug-naïve patients was published (13). It found that "group differences were small and clinically 
trivial, indicating that treatment with placebo medication was no less effective than conventional antipsychotic treatment".

In Denmark, compulsory hospitalisation or detention, which often lead to compulsory medication, may only take place if the patient is insane or in a similar state, and it would be irresponsible not to deprive the person of his liberty for the purpose of treatment because (i) the prospect of cure or a significant and decisive improvement in the condition would otherwise be significantly impaired; or (ii) the person presents an imminent and significant danger to himself or others (14). However, the legal protections for people diagnosed as mentally ill are clearly illusory and the system meant to protect them is a sham. Condition (i) is never met and Condition (ii) can only be met if the patient becomes so overdosed that he or she turns into a zombie. For example, a patient who had developed psychosis two years earlier had never received antipsychotics and did not want them, but the Appeals Board argued that she would be able to improve significantly and decisively with treatment. Antipsychotics cannot accomplish this.

Another questionable aspect is notes made in the patients' files; they may not be correct and changes may have been introduced later to cover up fatal mistakes (15). One of the patients noted that the psychiatrists do not listen and write something in the file other than what actually happened.

Antipsychotics are nothing but major tranquillisers, which was their original name, and if the staff have not been able to calm down a patient in an acute situation, benzodiazepines seem to be more effective than antipsychotics (16). It is a clear violation of Danish law that the patients were never offered benzodiazepines because forced medication should involve drugs with the fewest possible adverse effects (14). When we have asked, during our many public lectures, about psychiatric drugs, all patients have said they would rather have a benzodiazepine than an antipsychotic next time they developed a psychosis. Hence, both the law and the patients are being ignored. Additionally, several patients wanted psychotherapy, which randomised trials have shown can be effective (17-19).

\section{The abuse of diagnoses}

We had reservations about the psychiatrists' diagnoses of delusions in nine cases. There is an element of Catch-22 when a psychiatrist decides on a diagnosis and the patient disagrees. According to the psychiatrist, the disagreement shows the patient lacks disease insight, which is considered a proof of their mental illness.

The abuse involves psychiatrists using diagnoses or derogatory terms for things they do not like or do not understand. When patients did not like psychiatrists, the drugs, or being confined to a psychiatric ward, their defensive reactions were often used against them. One of us once joined the head of department on his rounds, and after having talked to a patient who appeared to be completely normal, the psychiatrist said that he was delusional because he had gone on the internet and claimed that antipsychotics were dangerous. A chief nurse said the same about a patient who had also carefully studied the harmful effects of antipsychotics.

The patients or their disease were blamed for virtually everything untoward that happened. We did not see a single admission that it was the psychiatrist or other staff who had escalated a situation by their insistence that the patients be treated with drugs they could not tolerate or did not want or with other forced measures. When a patient was put in belts for five weeks and was angry after this, it was not ascribed to the inappropriate use of force but to his mania. The psychiatrists did not seem to have any interest in trauma, whether they were previous ones or caused by themselves.

Non-compliance with the psychiatrists' ideas sometimes leads to punishment in other ways. A patient was discharged from a psychiatric centre in the community because she had refused drug treatment. Many patients have described such experiences when they do not want pills and when they see psychiatrists in private practice. The response they get is: "Well, then I cannot help you!" (6).

When the patients stopped their antipsychotics after discharge because they did not want them, the curious term "medicine failure" was used (in ten patients). Before having consulted a psychiatrist, we thought it meant that the drug did not work, but this term is used when the patients do not take their drug.

A similarly misleading term is "treatment resistant", which psychiatrists use when a drug does not work. Again, it puts the blame on the patient, who is perceived to have a particularly nasty form of the disease, even though the drugs are to blame because they do not really work for anyone.

Withdrawal reactions were not taken seriously, and we did not see this term being used even though many patients suffered from them. The psychiatrists focused on the patients' current condition and apparently did not consider that the reemergence of psychosis could be a harm of the antipsychotic rather than a psychosis that would have occurred anyway at this point in time.

Several patients had previously stopped taking the drug after every discharge, and for one of them, the Complaints Board emphasised that this had rendered her seriously psychotic but did not consider that it could be an abstinence psychosis, ie, a harmful effect of the drug because of the changes in the brain it had caused. At the board meeting, the patient's counsel informed the board that the patient could not tolerate drugs, but to no avail. As always, the expert resolved that she was treated to preserve her health.

Another patient received aripiprazole on "vital indication" because of catatonia, and the drug had "a pronounced effect ... already after the first injection". The patient was considered to have no disease insight because he did not believe that he suffered from catatonic schizophrenia, but that the symptoms were adverse effects of the drug. Since he responded so promptly to the drug, the patient was probably right and 
suffered from withdrawal symptoms. He was informed that his life would be endangered if he did not get the medication. However, when he appealed to the Complaints Board, they stopped the dispensing of the drug while the complaint was being considered.

\section{Is psychiatry in a state of madness?}

An anonymous person once said that, "Insanity is doing the same thing over and over again and expecting different results" (20). One of us tweeted about this in 2019:"Psychiatrists increase the dose, change to other drugs or use more than one drug of the same type. When drugs don't work, they should be stopped. And psychiatrists should be stopped." Four of the patients' responses illustrate the madness:

My loved one is experiencing akathisia and his consultant thinks that treating akathisia with yet a different antipsychotic is the right way to go?;

Feels like we don't have a choice and hardly any support to taper [off use of the drug];

A medication I went on caused psychosis. To treat the psychosis, the dose kept getting increased.I became a monster, and I lost everything;

Another definition of madness is administering poison and expecting your victim to heal."

Psychiatrists often say that patients lack insight into the disease, but do the psychiatrists have sufficient insight into their own actions? Doing the same thing over and over again and expecting different results is what they do all the time, and they often ignore what they do not want to see. One of the patients in our sample said that the psychiatrist forced her to take olanzapine to treat the psychosis, even though she maintained that the drugs she had received through 31 years had destroyed her life.

It took psychiatry 20 years to recognise tardive dyskinesia as an iatrogenic illness (9), even though it is one of the worst harms of antipsychotics and affects about 4-5\% of patients every year (21), which means that most patients in long-term treatment will develop it. In 1984, Poul Leber from the FDA extrapolated the incidence data and indicated that, over a lifetime, all patients might develop tardive dyskinesia (9). Three years later the president of the American Psychiatric Association said on an Oprah Winfrey show that tardive dyskinesia was not a serious or frequent problem (22). A particularly virulent form of tardive akathisia is where the patient is driven by a torture-like inner agitation that compels them to move their hands and feet nervously or pace frantically about in an effort to relieve the distress (23). Tardive psychosis, also called supersensitivity psychosis, is another common iatrogenic harm that is largely ignored (5).

\section{Limitations}

The information we had access to was scant. We suspect that there were many more substantial problems than those we uncovered; but acknowledge that we could also in some cases have overestimated the problems because we did not have the full picture. We conducted data extraction under difficult circumstances and therefore not in duplicate, by two independent observers. We tried to compensate for this by extracting verbatim quotes from the material we reviewed and by consulting each other and a psychiatrist when the text was ambiguous.

\section{Conclusions}

The power imbalance was extreme; the patients clearly felt misunderstood and ignored, their legal protection was a sham, and the harm done was immense. The violation of patient rights is a global problem. Mental health systems need to make reforms consistent with the human rights of mental health patients. We suggest that forced medication be abandoned.

Acknowledgment: We thank psychiatrist Klaus Munkholm for advice and for help with data extraction.

\section{Conflicts of interest and funding: None.}

Statement of similar work: None submitted elsewhere. We deal with administrative issues in another paper (our Reference 8 in this paper).

\section{References}

1. United Nations Convention on the Rights of Persons with Disabilities. General comment No. 1. Geneva:UNCRPD; 2014 May 19 [cited 2019 Nov 1]. Available from: https://documents-dds-ny.un.org/doc/UNDOC/GEN/ G14/031/20/PDF/G1403120.pdf?OpenElement

2. Leucht $S$, Kane JM, Etschel E, Kissling W, Hamann J, Engel RR. Linking the PANSS, BPRS, and CGI: clinical implications. Neuropsychopharmacology. 2006 Oct; 31(10):2318-25. doi:10.1038/sj.npp.1301147.

3. Khin NA, Chen YF, Yang Y, Yang P, Laughren LP. Exploratory analyses of efficacy data from schizophrenia trials in support of new drug applications submitted to the US Food and Drug Administration. J Clin Psychiatry. 2012 Jun; 73(6): 856-64. Doi: 10.4088/JCP.11 r07539.

4. Moncrieff J. The bitterest pills. Basingstoke: Palgrave Macmillan; 2013.

5. Whitaker R. Anatomy of an epidemic. New York: Broadway Books; 2015.

6. Gøtzsche PC. Deadly psychiatry and organised denial. Copenhagen: People's Press; 2015.

7. Gøtzsche PC. Forced drugging with antipsychotics is against the law: decision in Norway. Mad in America. 2019 May 4 [cited 2019 Nov 1]. Available from: https://www.madinamerica.com/2019/05/forceddrugging-antipsychotics-against-law/.

8. Gøtzsche PC, Vinther S, Sørensen A. Forced medication in psychiatry: Patients' rights and the law not respected by Appeals Board in Denmark. Clin Neuropsychiatry. 2019; 16 (5-6): 229-33. Doi: 10.36131/ clinicalnpsych2019050606.

9. Breggin P. Brain-disabling treatments in psychiatry: drugs, electroshock and the psychopharmaceutical complex. New York: Springer; 2007.

10. Sienaert $P$, Dhossche DM, Vancampfort D, de Hert M, Gazdag G. A clinical review of the treatment of catatonia. Front Psychiatry 2014 Dec 9; 5: 181. doi: 10.3389/fpsyt.2014.00181.

11. Gottstein J. Psychiatry: force of law. Psych Rights 2002 Nov [cited 2019 Nov 1]. Available from: http://psychrights.org/force_of_law.htm.

12. Danborg PB, Gøtzsche PC. Benefits and harms of antipsychotic drugs in drug-naïve patients with psychosis: A systematic review. Int J Risk Saf Med. 2019; 30(4):193-201. https://doi.org/10.3233/JRS-195063.

13. Francey SM, O'Donoghue B, Nelson B, Graham J, Baldwin L, Yuen HP, et al. Psychosocial intervention with or without antipsychotic medication for first episode psychosis: a randomized noninferiority clinical trial. Schizophr Bull Open. 2020 Mar 20; 1(1):sgaa015.https://doi.org/10.1093/ schizbullopen/sgaa015.

14. Ministry of the Interior and Health, Denmark. Bekendtgørelse af lov om 
anvendelse af tvang ipsykiatrien m.v. [Promulgation of the law on the use of coercion in psychiatry]. 2019 Sept 2[cited 2019 Nov 1]. Available from: https://www.retsinformation.dk/Forms/R0710.aspx?id=210196.

15. Christensen DC. Dear Luise: a story of power and powerlessness in Denmark's psychiatric care system. Portland: Jorvik Press; 2012.

16. Dold M, Li C, Tardy M, Khorsand V, Gillies D, Leucht S. Benzodiazepines for schizophrenia. Cochrane Database Syst Rev. 2012 Nov 14; 11(11):CD006391.Doi: 10.1002/14651858.CD006391.pub2

17. Morrison AP, Turkington D, Pyle M, Spencer H, Brabban A, Dunn G, et al. Cognitive therapy for people with schizophrenia spectrum disorders not taking antipsychotic drugs: a single-blind randomised controlled trial. Lancet. 2014 Apr 19; 383(9926): 1395-403. Doi: 10.1016/S01406736(13)62246-1.

18. Hutton P, Taylor PJ. Cognitive behavioural therapy for psychosis prevention: a systematic review and meta-analysis. Psychol Med. 2014 Feb; 44(3):449-68. Doi: 10.1017/S0033291713000354.
19. Moritz S, Veckenstedt R, Andreou C, Bohn F, Hottenrott B, Leighton L, et al. Sustained and "sleeper" effects of group metacognitive training for schizophrenia: a randomized clinical trial. JAMA Psychiatry. 2014 Oct; 71(10): 1103-11. Doi: 10.1001/jamapsychiatry.2014.1038.

20. Insanity is doing the same thing over and over again and expecting different results. 2017 March 23. https://quoteinvestigator. com/2017/03/23/same/.

21. Moncrieff J.Antipsychotic maintenance treatment: time to rethink? PLoS Med.2015 Aug; 12(8): e1001861. Doi: 10.1371/journal.pmed.1001861.

22. Karon BP. All I know about Peter Breggin. In: The International Center for the Study of Psychiatry and Psychology (editor). The Conscience of Psychiatry. The reform work of Peter R. Breggin, MD. New York: Lake Edge Press; 2009.

23. Breggin P. Psychiatric drug withdrawal: A guide for prescribers, therapists, patients, and their families. New York: Springer Publishing Company; 2013.

\section{APPEAL FOR DONATIONS TO THE FORUM FOR MEDICAL ETHICS SOCIETY}

The Forum for Medical Ethics Society (FMES), publisher of the Indian Journal of Medical Ethics (IJME), appeals to subscribers, contributors, readers, supporters and well-wishers of IJME and FMES to donate to its corpus and towards the publication of IJME. Contributions from both individuals and institutions are welcome.

FMES has published the journal on a shoestring budget, without a break, since 1993. The journal is known for being open access and spearheading discourse aimed at advancing social justice in health and ethics-centred healthcare and health research reform. It is recognised widely as an authoritative resource of knowledge in bioethics and allied areas of enquiry. FMES and IJME have not only sustained themselves but have grown over these past 25 years. Our ever-growing base of readers, contributors, and reviewers enables the publication of multiple and diverse perspectives on wide-ranging topical areas. We have also striven to upgrade the journal technically to keep up with the advances in publishing to widen our reach. This has been possible only because of your steadfast and sustained support.

We are committed to maintaining our editorial independence which is critical to safeguarding the scientific integrity of what we publish. Therefore, wider support from all those who are committed to social justice in health is essential.

FMES is registered under the Societies Registration Act, 1860 (Reg No: Mumbai-218-1995-G.B.B.D.D) and the Bombay Public Trusts Act, 1950 (Reg No: F-17441 Mumbai, 1995), and donations are eligible for tax exemption under Section 80G of the Income Tax Act, 1961

For more details on how to support us, write to admin@ijme.in or visit our website www.ijme.in/subscribe-support/

\section{SUPPORT OPEN-ACCESS ACADEMIC PUBLICATIONS, DONATE TO THE FMES CORPUS FOR THE PUBLICATION OF IJME!}

